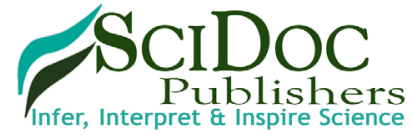

International Journal of Reproduction, Fertility \& Sexual Health (IJRFSH) ISSN: $2377-1887$

\title{
Inherited and Acquired Thrombophilia and Infertility in a Population of Brazilian Women
}

\author{
Study Report
}

AGS Soligo ${ }^{1 *}$, R.Barini ${ }^{1}$, Bizzacchi JA ${ }^{2}$

${ }^{1}$ Department of Obstetrics and Gynecology, University of Campinas Medical School, Campinas, São Paulo, Brazil.

${ }^{2}$ Department of Hematology, University of Campinas, Campinas, São Paulo, Brazil.

\section{Abstract}

Objective: To evaluate the relationship between thrombophilia and infertility

Design: Cross-sectional study

Setting: Assisted fertilization center

Patients: The infertile women $(\mathrm{n}=130)$ selected were receiving care at a private clinic in Campinas, São Paulo, Brazil. A control group was comprised ofhealthy fertile women $(n=260)$ who received care from a family planning outpatient clinic at the Women's Hospital (CAISM) of the University of Campinas (UNICAMP).

Interventions: Blood samples were taken from all participants. Positive tests were repeated 12 weeks later to exclude transitory antiphospholipid antibodies.

Main Outcome Measures: Determination of mutations in prothrombin genes, factor V Leiden, as well as deficiencies of protein C, protein S and antithrombin III (AT-III), anticardiolipin antibody, and lupus anticoagulant.

Results: Anticardiolipin antibodies were found in $10 \%$ of the infertile women and in $0.4 \%$ of the fertile women $(p<0.0001$; $\mathrm{OR}=3.61$ ), while lupus anticoagulant was found in $0.8 \%$ of the infertile group and in none of the fertile group (p 0.33 ;OR= 0.24). Protein $\mathrm{C}$ deficiency was found in $3.8 \%$ and $0.8 \%(\mathrm{p} 0.04 ; \mathrm{OR}=0.97)$, protein $\mathrm{S}$ deficiency in $5.4 \%$ and $0 \%(\mathrm{p}<0.0001$; $\mathrm{OR}=1.7)$, antithrombin deficiency in $3.8 \%$ and $0.4 \%(\mathrm{p}<0.01 ; \mathrm{OR}=1.2)$, Factor V Leiden in $3.1 \%$ and $1.5 \%(\mathrm{p} 0.45 ; \mathrm{OR}=$ 0.5 ), and prothrombin gene mutation $\mathrm{G} 20210 \mathrm{~A}$ in $2.3 \%$ and $1.9 \%$ ( $1.0 ; \mathrm{OR}=0.28$ ), respectively.

Conclusion: Acquired and Inherited thrombophilia, as evidenced by positive results for anticardiolipin antibody and natural anticoagulant deficiency (PC, PS, and AT) are more common in infertile women. However, prospective population studies are needed to confirm the data presented.

Keywords: Anticardiolipin Antibody; Lupus Anticoagulant; Antiphospholipid Antibody; Antithrombin Deficiency; Prothrombin Mutation.

\section{Introduction}

Infertility affects between one-fifth and one-sixth of reproductive-age couples. Around $10 \%$ of couples of reproductive age experience difficulty conceiving [1]. Currently, women tend to delay maternity as a function of their professional life, further hampering their reproductive capacity. In addition to the woman's age, various factors are associated with difficulties in conceiving. Endometrial receptivity has been the focus of investigative attention to evaluate the association between thrombophilic factors and infertility, since it involves vascularization during the embryo implantation process [2].
Thrombophilic factors may be acquired or inherited. The most studied inherited thrombophilic factors are: deficiencies of protein S (DPS), protein C (DPC), and antithrombin (DAT), Factor V Leiden mutation (FVL), and prothrombin mutation G20210A. Factors involved in acquired thrombophilia are antiphospholipid antibodies (anticardiolipin antibody [ACA] and lupus anticoagulant [LA]).

In 2004 it was recommended that the anti- $\beta 2$-glycoprotein I antibody be measured along with other antiphospholipid antibodies [3]. Its interference inthe trophoblast was also hypothesized to prevent adequate development of the placenta [4-6]. The role of antiphospholipid antibodies in obstetric complications has been

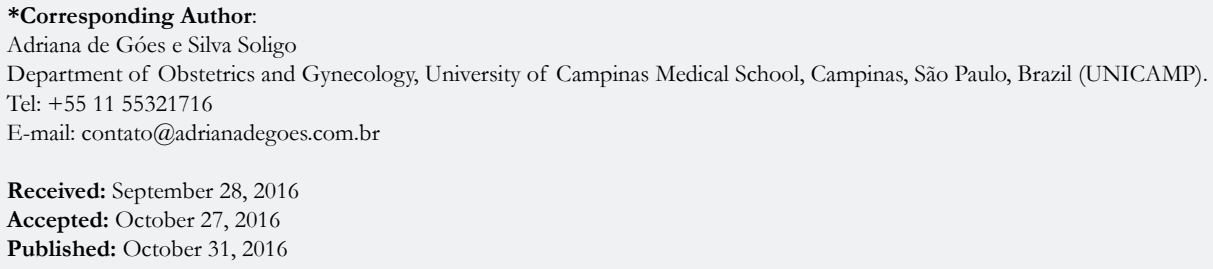

Copyright: AGS Soligo ${ }^{\circ}$ 2016. This is an open-access article distributed under the terms of the Creative Commons Attribution License, which permits unrestricted use, distribution and reproduction in any medium, provided the original author and source are credited. 
confirmed, but other studies have failed to identify any association between antiphospholipid antibodies and infertility [7, 8].

One study [9] with 45 infertile women showed that 32 women had thrombophilia: $71 \%$ inherited thrombophilia and 16\% genetic and acquired thrombophilia. The results suggested the importance of thrombophilic factors in the occurrence of infertility.Nevertheless, the high frequency of inherited thrombophilia in that study resulted fromthe inclusion of polymorphisms of the enzyme methylenetetrahydrofolate reductase, which are not widely accepted as thrombophilic factors in the literature. Other authors have corroborated the role of thrombophilia in infertility $[10]$.

On the other hand, another report evaluated the role of inherited and acquired thrombophilia in women with infertility of no apparent cause who were subjected to in vitro fertilization (IVF) [11]. Overall, 594 women were evaluated retrospectively and compared with two other groups of 637 fertile women and 17,337 women with no history of thromboembolism. None of the thrombophilias investigated were associated with a reduction in the IVF success rate. Furthermore, in women with Factor V Leiden and lupus anticoagulant, live birth rates were higher $(12.3 \%$ and $12.6 \%$, respectively) compared to women without thrombophilia (9\%). That study suggested that hypercoagulability is not associated with infertility and that investigation for thrombophilia should not be routine in women with infertility of no apparent cause.

The role of thrombophilia and infertility remains a controversial issue in the literature as of this writing. The objective of the present study is to clarify the relationship between acquired and inherited thrombophilia in infertile women compared to a control group of healthy fertile women.

\section{Materials and Methods}

\section{Patients}

This cross-sectional study investigated a control group of 130 infertile women and 260 fertile women to determine the association between acquired thrombophilic factors (anticardiolipin antibody and lupus anticoagulant), inherited thrombophilia (DPS, DPC, DAT, FVL, and prothrombin mutation G20210A), and infertility. The infertile women were selected by reviewing the files of patients receiving care at a private clinic between March 2003 and March 2005 [12]. All the women were white and aged over 18 years old, with primary infertility and unexplained infertility. Male or tubal factors were excluded.

The control group was composed of healthy fertile women who were selected at a family planning clinic at the Women's Hospital (CAISM) of the University of Campinas (UNICAMP) between April 2012 and March 2013. Inclusion criteria were white race, at least one previous term delivery, age 18 years of age or older, and no previous obstetric problems, no history of liver disease, hematological diseases, or infection.

\section{Samples}

Blood samples $(40 \mathrm{ml})$ were taken from all subjects. Positive tests were repeated 12 weeks later to exclude transitory antiphospholipid antibodies, in accordance with the Sydney Antiphospholipid Syndrome International Consensus [3]. Determination of mutations in prothrombin genes, factor $\mathrm{V}$ Leiden, as well as deficiencies of protein $\mathrm{C}$, protein $\mathrm{S}$ and antithrombin III (AT-III), anticardiolipin antibody, and lupus anticoagulant were performed as described else where [13].

Sample size was calculated using different sources based on the difference in the prevalence of thrombophilic factors between infertile and fertile women $[14,15]$. Considering a significance level of $5 \%$, a proportion of 2 fertile women for every infertile woman and a power of the test of $80 \%$, based on the formula developed by Pocock for the Chi-square test, a sample size of 390 women was calculated: 130 infertile women and 260 fertile women [16]. This sample was sufficient to analyze protein $\mathrm{C}$ deficiency and AT deficiency. Other factors were also evaluated with significant results.

\section{Statistical Analyses}

The Chi-square test and Fisher's exact test were used in the statistical analysis. Logistic regression was used to measure the association between the analyzed factors and infertility.

\section{Ethical Approval}

The Ethical Committee of the ABC School of Medicine approved the study protocol under reference number 153 on July 13, 2009. All patients signed an informed consent form, and ethical aspects were observed in accordance with the Declaration of Helsinki.

\section{Results}

The women evaluated in this study were all white. The mean age of the infertile women was $36 \pm 4.5$ years ( \pm standard deviation [SD]) compared to $34.2 \pm 8.1$ years for the fertile women.As for parity, $38 \%$ of the women in the fertile group had had two previous term deliveries and $25 \%$ had three or more children. Of the non-hormonal contraceptive methods used by the fertile women, $71 \%$ used the $\mathrm{TCu} 380 \mathrm{~A}$ intrauterine device (IUD). Regarding marital status, most of the fertile women (82\%) and all of the infertile women were in a stable union. In the group of infertile women, the mean time of infertility was $5.0 \pm 3.3$ years. The results are shown in Table 1 .

Anticardiolipin antibody was evaluated in 252 fertile women. Eight women were excluded from the study because their tests were not processed as a result oftechnical problems. Of the 252 fertile women, the result was abnormal in one case $(0.4 \%)$, and a retest confirmed the positive result.

Of the 130 infertile women, $13(10 \%)$ tested positive for anticardiolipin antibody and all of these results were confirmed by repeat testing. The difference between the infertile and fertile women was significant $(p<0.0001)$. We also tested for lupus anticoagulant in the 130 infertile women and the 260 fertile women. Of the infertile women, one tested positive and this result was confirmed 12 weeks later. No participantsin the fertile group tested positive. The difference between the two groups was not significant. 
Table 1. Comparison of Acquired Thrombophilic Factors between the Case Group (Infertile Women) and the Control Group (fertile women).

\begin{tabular}{|c|c|c|c|c|c|c|c|c|c|c|}
\hline & Infertile & & Fertile & & p-value & \multicolumn{3}{|c|}{ OR (IC 95\%) } & \multicolumn{2}{|c|}{ OR (IC 95\%) } \\
\hline Factor Evaluated & $\mathbf{N}$ & $\%$ & $\mathbf{N}$ & $\%$ & & & & & Adjuste & \\
\hline \multicolumn{2}{|c|}{ Anticardiolipin antibody } & & & & $<0.0001$ & 27.89 & 3.61 & 215.73 & & \\
\hline Not evaluated & 0 & & 8 & & & & & & & \\
\hline Positive & 13 & $10.00 \%$ & 1 & $0.4 \%$ & & & & & 3.75 & 250 \\
\hline Negative & 117 & $90.00 \%$ & 251 & $99.6 \%$ & & & & & & \\
\hline \multicolumn{2}{|c|}{ IgM Anticardiolipin antibody } & & & & $<0.0001$ & 16.46 & 2.04 & 133.09 & & \\
\hline Not evaluated & 0 & & 8 & & & & & & & \\
\hline Positive & 8 & $6.20 \%$ & 1 & $0.4 \%$ & & & & & & \\
\hline Negative & 122 & $93.80 \%$ & 251 & $99.6 \%$ & & & & & & \\
\hline \multicolumn{2}{|c|}{ IgGAnticardiolipin antibody } & & & & 0.007 & 12.15 & 1.45 & 101.99 & & \\
\hline Not evaluated & 0 & & 8 & & & & & & & \\
\hline Positive & 6 & $4.60 \%$ & 1 & $0.4 \%$ & & & & & & \\
\hline Negative & 124 & $95.40 \%$ & 251 & $99.6 \%$ & & & & & & \\
\hline \multicolumn{11}{|c|}{ Lupus anticoagulant } \\
\hline Not evaluated & 0 & & 0 & & 0.33 & 6.03 & 0.24 & 149.18 & & \\
\hline Positive & 1 & $0.80 \%$ & 0 & $0.0 \%$ & & & & & & \\
\hline Negative & 129 & $99.20 \%$ & 260 & $100.0 \%$ & & & & & & \\
\hline
\end{tabular}

OR: odds ratio; 95\% CI: 95\% Confidence Interval.

The frequency of each inherited thrombophilic factor evaluated is shown in Table 2. Protein C deficiency was abnormal in 5/130 infertile women (3.8\%), with abnormal results being confirmed following vitamin $\mathrm{K}$ deficiency treatment. Protein $\mathrm{C}$ was evaluated in 256/260 fertile women. Four women were excluded because they did not return to repeat the test after vitamin $\mathrm{K}$ treatment. Abnormal results were confirmed in two fertile women $(0.8 \%)$. A statistically significant difference was found between the two groups (p $0.04 ; \mathrm{OR}=0.97)$.

Protein S deficiency was identified in 7/130 infertile women $(5.4 \%)$. In the fertile group, this test was performed in $247 / 260$ women, but 13 were excluded because their test was not processed due to technical problems. There were no abnormal findings in any of the fertile women. Protein S deficiency was significantly more common in the group of infertile women, with an almost two-fold greater risk of protein $\mathrm{S}$ deficiency in the infertile group in relation to the fertile group $(\mathrm{p}<0.0001 ; \mathrm{OR}=1.7)$.

Antithrombin deficiency was found in $5 / 130$ of the infertile women $(3.8 \%)$ compared to only $1 / 260(0.4 \%)$ of the fertile women evaluated. There was a significant difference between the two groups ( $\mathrm{p} 0.01 ; \mathrm{OR}=1.2$ ).

Factor V mutation, referred to as FVL, was found in 4/130 (3.1\%) of the infertile women and in 4/260 (1.5\%) of the fertile women, with no significant difference between the groups.

The prothrombin mutation G20210A was present in 3/130 infertile women $(2.3 \%)$ and in $5 / 260$ of the fertile women $(1.9 \%)$, with no significant difference between the groups.

\section{Discussion}

The results of the present study show an increase in the frequency of anticardiolipin antibodies and natural anticoagulants deficiency (PC, PS, and AT) in infertile women.Infertile women were almost four times more likely to have anticardiolipin antibodies and two times more likely to have protein $\mathrm{S}$ deficiency compared to the group of fertile women, and this difference was significant. Due to the low frequency in the fertile women, prospective population studies are needed to confirm the data presented.

Infertile women were selected for this study, rather than only those with implantation failure, in an attempt to increase sample size and obtain significant differences. The infrequency of this disease, the limitations involved in identifying women with implantation failure, and the high cost make it unfeasible to conduct a study with those characteristics in this setting. The sample size was calculated to achieve $80 \%$ statistical power. This sample of 390 women was sufficient to analyzeprotein $\mathrm{C}$ deficiency and AT deficiency. Other factors were also evaluated with significant results.

A 2014study [17] reported a greater frequency of antiphospholipid antibodies in cases of implantation failure. Those authors evaluated the frequency of antiphospholipid antibodies, particularly the anti- $\beta 2$-glycoprotein I antibody, in a group of 40 women in whom implantation had failed, comparing them with a control group of 100 healthy female blood donors. Our study showed also an association between APA and infertility, although we did not evaluate anti- $\beta 2$-glycoprotein I antibody.

Another study [9] reported a greater frequency of inherited and acquired thrombophilia in women with infertility. Nevertheless, 
Table 2. Comparison between Infertile Women (Case Group) and Fertile Women (Control Group) According to the Presence of Thrombophilic Factors.

\begin{tabular}{|c|c|c|c|c|c|c|c|c|}
\hline \multirow{2}{*}{ Factor Evaluated } & \multicolumn{2}{|c|}{ Infertile } & \multicolumn{2}{|c|}{ Fertile } & \multirow{2}{*}{ p-value } & \multirow{2}{*}{\multicolumn{3}{|c|}{ OR $(95 \% \mathrm{CI})$}} \\
\hline & $\mathbf{N}$ & $\%$ & $\mathrm{n}$ & $\%$ & & & & \\
\hline \multicolumn{9}{|c|}{ Protein $C$ deficiency } \\
\hline Not evaluated & 0 & 0.0 & 4 & & & & & \\
\hline Deficient & 5 & 3.8 & 2 & 0.8 & & 5.08 & 0.97 & 26.55 \\
\hline Normal & 125 & 96.2 & 254 & 99.2 & 0.0458 & & & \\
\hline \multicolumn{9}{|c|}{ Protein S deficiency } \\
\hline Not evaluated & 0 & 0.0 & 13 & & & & & \\
\hline Deficient & 7 & 5.4 & 0 & 0.0 & & 30.06 & 1.70 & 530.66 \\
\hline Normal & 123 & 94.6 & 247 & 100.0 & $<0.0001$ & & & \\
\hline \multicolumn{9}{|c|}{ Antithrombin deficiency } \\
\hline Deficient & 5 & 3.8 & 1 & 0.4 & & 10.36 & 1.20 & 89.62 \\
\hline Normal & 125 & 96.2 & 259 & 99.6 & 0.0171 & & & \\
\hline \multicolumn{9}{|c|}{ Factor V Leiden** } \\
\hline Present & 4 & 3.1 & 4 & 1.5 & & 2.03 & 0.50 & 8.26 \\
\hline Absent & 126 & 96.9 & 256 & 98.5 & 0.4491 & & & \\
\hline \multicolumn{9}{|c|}{ Prothrombin mutation ${ }^{* *}$} \\
\hline Present & 3 & 2.3 & 5 & 1.9 & 1.0000 & 1.20 & 0.28 & 5.12 \\
\hline
\end{tabular}

** Heterozygous mutation. OR: odds ratio; 95\%CI: 95\% confidence interval.

since it was a prevalence study, it was not possible to confirm any association between thrombophilia and infertility. Our study suggests that there is an association between thrombophilia and infertility.

Another report conducted with a larger population sample failed to evaluate natural anticoagulants and found no significant association between thrombophilia and infertility [14]. In that casecontrol study, 234 infertile women were compared to 234 fertile women. The factors evaluated were: antiphospholipid antibodies (LA andACA), FVL, prothrombin mutation G20210A, and MTHFR mutation C677T. The study found no greater incidence of thrombophilia in the group of infertile women. The data from the report cited were corroborated by investigators in Israel, who evaluated 594 women with infertility of no apparent cause and compared them to 637 fertile women and to 17,337 women with no history of venous thromboembolism [11]. Those authors evaluated acquired and inherited thrombophilia and found no statistically significant difference between the study groups. Therefore, they did not recommend screening for thrombophilia or the use of antithrombotic therapy in women with infertility of no apparent cause. This Israeli study included women who had undergone atleast one thrombophilic factor test. Not all factors were evaluated throughout the sample population as in our investigation. However, ourstudy shows that the search for natural anticoagulants mightbe important for this group of patients.

In 2014, Grandone et al., suggested that the presence of hypercoagulability at the implantation site could have a negative effect on pregnancy rates, and recommended anticoagulant therapy in in vitro fertilization cycles. This author selected 1,107 women who had undergone in vitro fertilization and evaluated the association between antithrombotic treatment, pregnancy rates, and live birth rates. Results showed better pregnancy and live birth rates in the group subjected to antithrombotic therapy. Our study suggests that anticardiolipin antibody and natural anticoagulant deficiencies are more common in infertile women, but we do not recommend antithrombotic treatment, except in women in whom hypercoagulability has been confirmed [18].

In 2011, Di Nisio et al., conducted a systematic review on thrombophilia and its effects on assisted reproduction. The case-control studies suggested a greater frequency of antiphospholipid antibodies in infertile women, particularly in the subgroup of women with failed implantation. Nevertheless, the prospective cohort studies which were evaluated failed to confirm this finding. Screening for thrombophilia prior to assisted reproductive techniques has not been recommended, and instead individualized analysis of each case is advocated [19]. Although studies with large sample sizes are needed to confirm our hypothesis, the investigation of thrombophilia demonstrates its worth if it can select patients with greater pregnancy rates when treated.

It is important to consider women who successfully conceive and who have thrombophilia. Morbidity during pregnancy is higher in these patients, and possible complications include preeclampsia, intrauterine growth restriction, placental abruption, premature delivery, recurrent pregnancy loss, and chronic fetal distress in addition to ischemic events during pregnancy [7, 8, 20-22]. Appropriate treatment of this group may increase the chances of a better pregnancy result.

\section{Conclusion}

Investigation of acquired and inherited thrombophilia should be considered, particularly anticardiolipin antibody and protein S de- 
ficiency. However, prospective population studies are needed to confirm the data presented.

\section{Declarations}

This study received financial support from the São Paulo Foundation for the Support of Research (FAPESP) under grant number 2010/09615-0. The sponsor had no involvement in the study design, in the collection, analysis or interpretation of data, in the writing of the report, or in the decision to submit the article for publication.

\section{References}

[1]. Practice Committee of American Society for Reproductive M (2013) Definitions of infertility and recurrent pregnancy loss: a committee opinion. Fertil Steril. 99(1): 63.

[2]. Simon A, Laufer N (2012) Assessment and treatment of repeated implantation failure (RIF). J Assist Reprod Genet. 29(11): 1227-39.

[3]. Branch DW (2005) Summary of the 11th International Congress on antiphospholipid autoantibodies, Australia, November 2004. J Reprod Immunol. 66(1): 85-90.

[4]. Ichikawa G, Yamamoto T, Chishima F, Nakamura A, Kuno S, et al., (2011) Effects of anti-beta2-glycoprotein I antibody on PIGF, VEGF and sVEGFR1 production from cultured choriocarcinoma cell line. J Obstet Gynaecol Res. 37 (8): 1076-83.

[5]. Kovacs M, Hartwig M, Aleksza M,Tihanyi M, Nagy T, et al., (2012) Antiphospholipid antibodies in relation to sterility/infertility. Hum Immunol. 73(7): 726-31

[6]. Miyakis S, Lockshin MD, Atsumi T, Branch DW, Brey RL, et al., (2006) International consensus statement on an update of the classification criteria for definite antiphospholipid syndrome (APS). J Thromb Haemost. 4(2): 295-306.

[7]. De Jesus GR, Agmon-Levin N, Andrade CA, Andreoli L, Chighizola CB, et al., (2014) $14^{\text {th }}$ International Congress on Antiphospholipid Antibodies Task Force report on obstetric antiphospholipid syndrome. Autoimmun Rev. 13(8): 795-813.

[8]. Pantham P, Abrahams VM, Chamley LW (2016) The role of anti-phospholipid antibodies in autoimmune reproductive failure. Reproduction. 151(5): R79-90.
[9]. Petukhova NL, Tsaturova KA, Vartanian EV, Schigoleva AV, Markin AV (2014) Study of the frequency of occurrence of genetic and acquired thrombophilia in infertile women prior IVF. Gynecol Endocrinol. 30(1): 32-34.

[10]. Ivanov P,Tsvyatkovska T, Konova E, Komsa-Penkova R (2012) Inherited thrombophilia and IVF failure: the impact of coagulation disorders on implantation process. Am J Reprod Immunol. 68(3): 189-198.

[11]. Steinvil A, Raz R, Berliner S, Steinberg DM, Zeltser D, et al., (2012) Association of common thrombophilias and antiphospholipid antibodies with success rate of in vitro fertilisation. Thromb Haemost. 108(6): 1192-11977.

[12]. Soligo A, Barini R, Carvalho E, Annichino-Bizzacchi J (2007) Prevalence of thrombofilic factors in infertile women. Rev Bras Ginecole Obstetrícia. 29(5): 235-240.

[13]. Kupferminc MJ, Eldor A, Steinman N, Many A, Bar-Am A, et al., (1999) Increased frequency of genetic thrombophilia in women with complications of pregnancy. N Engl J Med. 340(1): 9-13.

[14]. Martinelli I, Taioli E, Ragni G, Levi-Setti P, Passamonti SM, et al., (2003) Embryo implantation after assisted reproductive procedures and maternal thrombophilia. Haematologica. 88(7): 789-793.

[15]. Qublan HS, Eid SS, Ababneh HA, Amarin ZO, Smadi AZ, et al., (2006) Acquired and inherited thrombophilia: implication in recurrent IVF and embryo transfer failure. Hum Reprod. 21(10): 2694-2698.

[16]. Pocock S (1983) Clinical Trials: a practical approach. (5th Edn), Wiley, Chichester, UK.

[17]. Paulmyer-Lacroix O, Despierres L, Courbiere B, Bardin N (2014) Antiphospholipid antibodies in women undergoing in vitro fertilization treatment: clinical value of IgA anti-beta2glycoprotein I antibodies determination. Biomed Res Int. 2014: 314704.

[18]. Grandone E, Villani M, Tiscia GL, Dentali F, Colaizzo D, et al., (2014) Clinical Pregnancies and Live Births in women approaching ART: a followup analysis of 157 women after thrombophilia screening. Thromb Res. 133(2): 168-172.

[19]. Di Nisio M, Rutjes AW, Ferrante N, Tiboni GM, Cuccurullo F, et al., (2011) Thrombophilia and outcomes of assisted reproduction technologies: a systematic review and meta-analysis. Blood. 118(10): 2670-2678.

[20]. Chighizola CB, de Jesus GR (2014) Antiphospholipid antibodies and infertility. Lupus. 23(12): 1232-1238.

[21]. Kutteh WH, Hinote CD (2014) Antiphospholipid antibody syndrome. Obstet Gynecol Clin North Am. 41(1): 113-132.

[22]. R B, J A-B, E C, ML N, AG S, et al., (2013) Main types of clinical appearance of thrombophilic states: pregnancy-target groups for thrombophilia test. in Pregancy Thrombophilia- the unsuspected risk. InTech: Croatia. 